www.jmscr.igmpublication.org

Impact Factor 5.84

Index Copernicus Value: 71.58

ISSN (e)-2347-176x ISSN (p) 2455-0450

crossref DOI: _https://dx.doi.org/10.18535/jmscr/v5i9.160

Journal Of Medical Science And Clinical Research

\title{
Awareness of Biomedical Waste Management among MBBS Students at a Tertiary Care Teaching Hospital in Mewat, Haryana
}

\author{
Authors \\ Prakriti Vohra $^{1}$, Nidhi Sharma ${ }^{1 *}$, Pratibha Mane ${ }^{2}$, Gini Garima ${ }^{3}$, Abhishek Sharma ${ }^{4}$, \\ Nikita Singh 5 \\ ${ }^{1}$ Assistant Professor, Department of Microbiology, SHKM, GMC, Nalhar, Mewat \\ ${ }^{1 *}$ Demonstrator, Department of Microbiology, SHKM, GMC, Nalhar, Mewat \\ ${ }^{2}$ Professor and Head, Department of Microbiology, SHKM, GMC, Nalhar, Mewat \\ ${ }^{3}$ Associate Professor, Department of Biochemistry, SHKM, GMC, Nalhar, Mewat \\ ${ }^{4}$ Associate Professor, Department of Biochemistry, SHKM, GMC, Nalhar, Mewat \\ ${ }^{5}$ Demonstrator, Department of Biochemistry, SHKM, GMC, Nalhar, Mewat \\ Corresponding Author \\ Dr Nidhi Sharma \\ Demonstrator, Department of Microbiology, SHKM, GMC, Nalhar, Mewat \\ Email:drnidz@gmail.com,8605900794
}

\begin{abstract}
Introduction: Biomedical waste is any waste, which is generated during the diagnosis, treatment or immunization of human beings or in research activities or in the production or testing of biological products. Biomedical waste can be categorized into non-hazardous and bio-hazardous. Approximately 75$90 \%$ of the biomedical waste are non hazardous and as harmless as any other municipal waste. The remaining 10-25\% is hazardous and can be injurious to humans or animals and deleterious to environment. Inadequate and inappropriate knowledge of handling of healthcare waste may have serious health consequences and a significant impact on the environment as well. Hospitals/health care services inevitably create waste that may itself be hazardous to health. The waste produced in the course of health care activities carries a higher potential for injury, infection and pollution due to open burning, than any other type of waste.

Objective: The objective was to assess awareness about biomedical waste management of MBBS student. Materials and Methods: This was a cross-sectional study done in a medical college l. A total of 100 MBBS students were included in the study with their prior consent.

Results: $70 \%$ were boys and 30\% were girl students. Among various questions asked in the questionnaire, the overall awareness of MBBS students was $63.45 \%$.

Conclusion: Lack of appropriate knowledge about biomedical waste management impacts practices of proper waste disposal. Hence, the importance of training regarding health care waste management needs emphasis.
\end{abstract}




\section{Introduction}

Waste generated during the diagnosis, treatment or production of biological products for humans or animals is called Biomedical waste (BMW). The main sources of biomedical waste are Hospitals, medical clinics and laboratories. ${ }^{1}$ Various categories of BMW are mentioned in schedule 1 of biomedical waste management (BMWM) and handling rules, $1998 .^{2}$ waste generation rate ranges from 0.5 to $2.0 \mathrm{~kg}$ per bed per day. Every year, 0.33 million tonnes of BMW is generated in India. Safe and reliable method of handling of Biomedical waste is essential at point of generation of waste. ${ }^{3}$ since the implementation of Bio-medical waste rules (1998), every health care personnel is expected to have a proper knowledge about collection, handling and disposal of biomedical waste for proper management of the same. ${ }^{4}$

The lack of awareness has led to hospitals becoming hub of spreading disease rather than working towards eradicating them. Biomedical waste management (BMW) is a team work. A conscious, cooperative and coordinated effort is required from doctors to ward boys and for efficient working of biomedical waste management team. ${ }^{5}$ This study was conducted among MBBS students studying in SHKM, GMC, Mewat to assess awareness about various aspects of biomedical waste management (BMW) among them, so that an effective stratergy can be developed for improving situation in future.

\section{Materials and Methods}

This study was conducted at Shaheed Hasan Khan Mewati, Govt. Medical College and hospital, Mewat, Haryana. Study design was cross sectional in nature. A self distributed, pre-tested questionnaire was distributed among MBBS students (first year till final year). It comprised of questions to test awareness regarding BMWM. Percentage method was used in the current study.

\section{Results}

A total of 100 students participated in this study. $70(70 \%)$ were boys and rest were girl students (30\%). Our study showed that only $42 \%$ of students had heard about BMW (Management and Handling) rule, 1998 . While only $58 \%$ of students knew about number of categories of biomedical waste only $8 \%$ could recall details of these categories. $65 \%$ of participants knew about various methods of disposal of biomedical waste.85\% of MBBS students knew about diseases caused due to improper handling and management of biomedical waste. $74 \%$ of them knew about importance of HBV vaccination among staff handling BMW. 56.75\% of students could answer correctly use of colour coded biomedical waste bags and bins depending upon nature of waste generated.

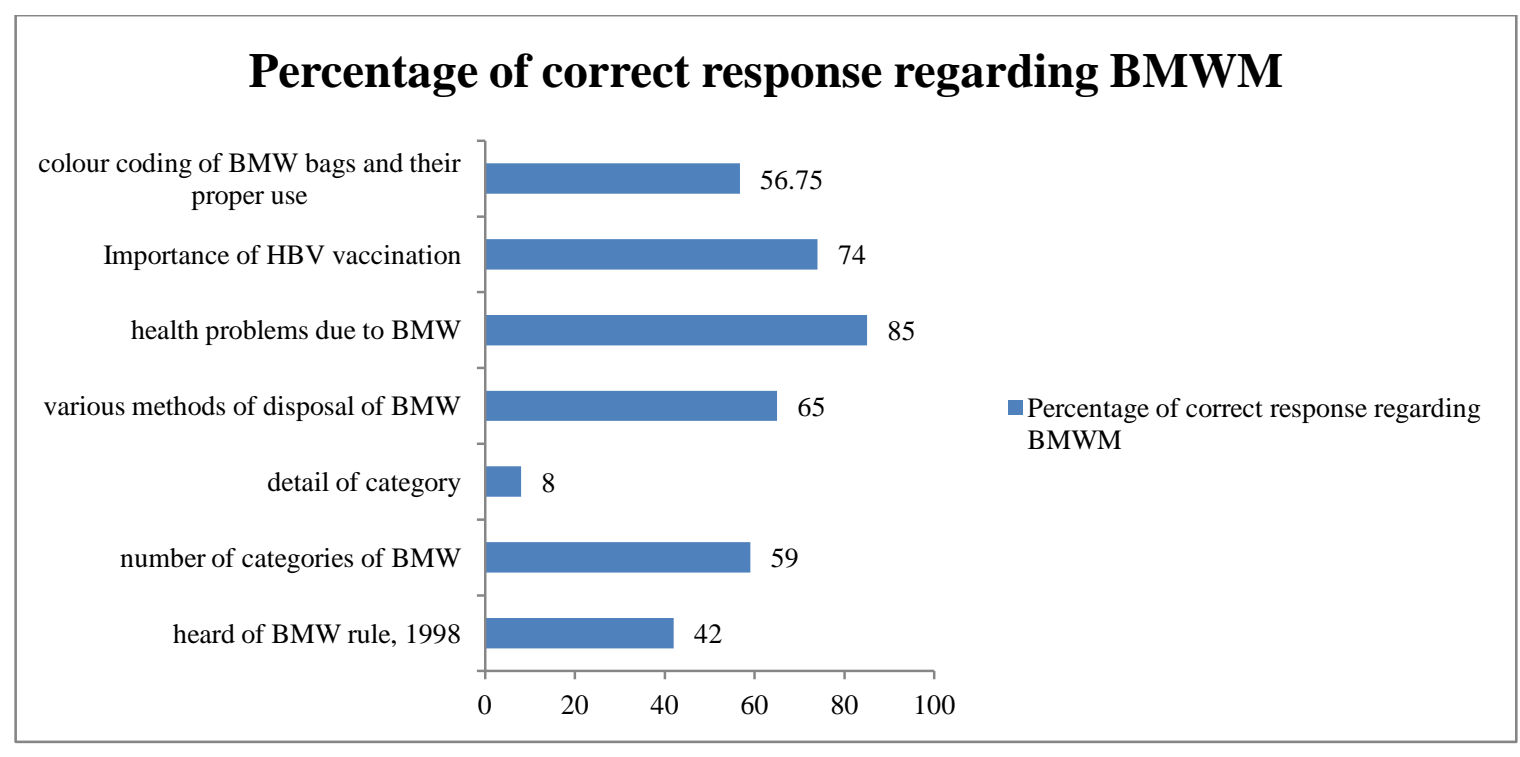




\section{Discussion}

In this study, MBBS students were assessed about their knowledge of biomedical waste management. Interestingly, study revealed that their awareness was moderately satisfactory indicating lack of required knowledge of biomedical waste management.

$42 \%$ of MBBS students had knowledge about BMW rule,1998 in our study. In a study by Saini et $\mathrm{al}^{6}, 99.1 \%$ of study participants knew about this law. This difference in knowledge may be due to difference of experience and exposure among MBBS (undergraduate students), junior residents and senior consultants. A study by Deo et $\mathrm{al}^{7}$, revealed $47.58 \%$ of doctors were aware about legislation on BMWM similar to that of our study. There were ten categories of BMW which was known by $59 \%$ of study participants. A study at Andhra Pradesh showed that only $1.6 \%$ of their study population knew about these categories, which may be due to the fact that their study population consisted of paramedical staff. ${ }^{8} 28 \%$ of MBBs students knew exact number of categories of biomedical waste in a study by Bhardwaj M. et $\mathrm{al}^{9}$.this difference may be due to quality of training imparted to students to improve their current knowledge.

\section{Details of category}

$65 \%$ of participants knew about various methods of disposal of biomedical waste in the present study. Our results match with study conducted by Nema S. Et al ${ }^{10}$. While, in a study by Bhardwaj et $\mathrm{al}^{9}$; only $20.9 \%$ of students could accurately determine various methods of disposal of biomedical waste. This difference may be due to less number of repeated training imparted to students.

Awareness regarding health hazards related to improper BMWM among study participants was found to be $85 \%$ in contrast to study by Narang et $\mathrm{al}^{11}(100 \%)$. Whereas, only $63.46 \%$ of doctors were aware on same issue in study at New Delhi by Bhagwati et al ${ }^{12}$.
$74 \%$ of the undergraduate students knew about importance of $\mathrm{HBV}$ vaccination among staff handling BMW in present study. $94 \%$ of MBBS students knew about the same in the study by Bhardwaj et al ${ }^{9}$ whereas in a study by Makadia J S et al ${ }^{12} 58 \%$ students were aware about HBV vaccination. This difference may be due to difference in training intervals at the various institutes.

Different color coding bags for segregation is one of the most important steps of biomedical waste management. Only $56.75 \%$ of our study participants displayed their casual approach regarding use of color coding bags/bins which is in contrast to study by Selvaraj et al. ${ }^{13}$ Deo et al showed only $20.23 \%$ of doctors knew the same whereas only $26 \%$ of participants knew correctly regarding the same in a study by Joe et al. ${ }^{14}$

\section{Conclusion}

Based on the observation, regular and effective training of the medical students is important regarding bio medical waste management. Regular and periodic assessment of level of Awareness regarding biomedical waste management (BMW) management should to be conducted among the medical students.

It is recommended that it should be made mandatory for medical and paramedical institute to train their students before they start their clinical posting in hospital by lectures as well as by demonstration. These training sessions be onetime activity but rather a continuous process according to the patient input in different healthcare facilities. This will increase effectiveness of BMW management among future doctors.

\section{Bibliography}

1. Gordon JG, Rein PA. Medical waste management. Hospital epidemiology and infection control. 2004;3:1773-85.

2. Bio-medical waste (Handling and Management) Rules 1998.available from http://www.moef.nic.in/legis/hsm/biomed. html. (last assessed on ) 
3. Patil AD, Shekhar AV. Health-care waste management in India. $\mathrm{J}$ Environment Manage.2001;63:211-20.

4. Ministry of environment, Forests and climate change, Government of India. Draft Bio-medical waste (Management and Handling) rules, 2016. Available from: http://moef.nic.in/sites/default/files/Final_ vetted_BMW\%20 Rules\%202015.pdf [Last accessed on ]

5. Basu M., Das P., Pal R. Assessment of future physicians on biomedical waste management in a tertiary care hospital of West Bengal. J Nat Sci Biol Med.2012 Jan-Jun; 3 (1):38-42.

6. Saini S, Nagarjun SS, Sharma RK. Knowledge, Attitude and Practices of BioMedical Waste Management amongst staff of a tertiary level hospital in India. J Acad. Hosp.Adm.2005;17:1-12

7. Deo D, Tak SR, MundeSS. A study of knowledge regarding biomedical waste management among employees of a tertiary care hospital in rural area. J Indian soc hosp waste Manage.2006;5:12-6.

8. Shafee Mohd., Kasturwar N., NirupamaN. Study of Knowledge, attitude and Practices regarding biomedical waste among Paramedical workers. Indian J community medicine.2010;35:369-70.

9. Bhardwaj M., Joshi R. et al. Awareness of biomedical waste management (BMW) among undergraduate medical students of Punjab. EJPMR.2016; 3(4): 263-65.

10. Nema S., Singh A., Tripathi K., Shidhaye P., Dhanvijay A. Biomedical waste management : A study of knowledge, practices and attitude among health care personnel at a tertiary care hospital in Bhopal, central India. JMSCR.2015; 3(5): 5844-55.
11. Narang RS, Manchanda A, Singh S, verma N, Padda S. Awareness of biomedical waste management among dental professionals and auxiliary staff in Amristsar, India. Oral Health Dent Management 2012;11:162-8.

12. Bhagwati G.,Nandwani S, Singhal S. Awareness and practices regarding biomedical waste management among health care workers in a tertiary care hospital in Delhi. IJMM;2015;33(4):580-2.

13. Selvaraj K., sivaprakasam P., Nelson SB,Kumar Gh,Norman P.,Pandiyan KR. Knowledge and practice of biomedical waste (BMW) management among medical practitioners of Kanchipuram Town, India.Int J Curr microbial appl Sci 2013;2:262-7.

14. Hospital waste management in union territory of Pondicherry- An exploration . principal investigator-Dr. Joe Joseph, coinvestigator-Dr. C.G.Ajith Krishnan.2003-04.] available from: http://www.pon.nic.in/citizen/science/ppcc -new/Joe.

15. Makadia JS,Joshi A,Gohel M .Importance of clinical posting for awareness on biomedical waste in medical and paramedical students, IJMEDPH,vol 4,issue 4,2014,377-9. 